\title{
Respiratory Complications in Trauma Patients: A Multidisciplinary Approach to Prevention
}

As many as half of all trauma admissions in the United States admitted to an ICU require mechanical ventilation, and $>80 \%$ of trauma patients who suffer an in-hospital complication will end up in respiratory failure on the ventilator. ${ }^{1}$ Fully $2.5 \%$ of all trauma patients admitted to the ICU in 2013 in the United States were there due to an unplanned intubation. Respiratory complications following traumatic injury, therefore, represent a significant burden for the nation's trauma systems and should be examined carefully for ways to mitigate this impact. Although much has been written regarding risk factors for respiratory compromise overall, trauma patients represent a unique entity that has been relatively underrepresented in the respiratory care literature. This is a population that tends to be younger and have fewer underlying comorbidities but are disproportionately affected by concurrent injury to multiple physiologic systems: hematologic, cardiovascular, neurologic, musculoskeletal, and often direct injury to the respiratory system itself. ${ }^{2}$ Furthermore, the use of powerful respiratory suppressants in the form of opioids and benzodiazepines to treat the resultant pain and anxiety as well as sometimes multiple trips to the operating room during the same admission can have an additive impact on respiratory function over the hospital course of the more severely injured patients. ${ }^{3,4}$ Last, often profound derangements of the immunological system can both be the drivers of inflammation leading to conditions like ARDS and lead to an immunocompromised state increasing susceptibility to pneumonia, empyema, and other respiratory complications. ${ }^{5}$ In a landmark study ${ }^{6}$ of independent risk factors for developing respiratory complications among trauma subjects, injury severity score was chief among them with odds ratios for the development of pneumonia, atelectasis, respiratory failure, and ARDS at 9.6, 7.4, 6.3, and 15.5, respectively. Respiratory complications, therefore, are a significant and potentially preventable source of morbidity and mortality among trauma patients. It is imperative,

\footnotetext{
Mr Forrette has disclosed relationships with Covidien, Ohmeda, and Medical Specialties. Dr Greiffenstein has disclosed no conflicts of interest.
}

Correspondence: Patrick Greiffenstein MD, 1542 Tulane Ave, New Orleans, LA 70112. E-mail: pgreif@1suhsc.edu.

DOI: $10.4187 /$ respcare.05284 therefore, that hospitals receiving and treating these patients recognize and avoid the potentially life-threatening complications that can arise with repeated and concomitant insults.

See the Original Study on Page 1580

The study by Nyland et $\mathrm{al}^{7}$ in this issue of RESPIRATORY CARE highlights several important aspects of this effort. First is the importance of recognizing risk factors among patients who otherwise may not have been at risk of respiratory failure and instituting a program of increased vigilance and proactive measures to identify and mitigate risk factors for respiratory embarrassment and resultant complications. The authors used a simple algorithm for identification of subjects who would be at highest risk due to both preexisting pulmonary insults (COPD, asthma) and direct compromise of the respiratory system (pulmonary contusions, rib fractures) and followed up with bedside assessment and preventive strategies for providing lung expansion, airway clearance, and bronchodilator therapy when indicated.

Second, the authors illustrated the obstacles of implementing a respiratory care protocol, as evidenced by the poor adherence of the initial post-protocol phase of their study. The authors noted that, when left to the discretion of the treating physician, many eligible patients were not enrolled and the impact of the protocol was not as significant overall. This highlights the challenges of instituting new treatment measures in any care setting and the importance of a protocol-based initiation of therapy that bypasses the need for physician involvement and allows the protocol initiation by respiratory therapists. The authors noted that the success of the program was dependent on respiratory therapist determination of the indicated therapy based on a departmental algorithm rather than reliance on physician evaluation. It has been demonstrated, in particular among trauma patients with respiratory compromise, that a multidisciplinary approach to management reduces morbidity and mortality. ${ }^{4}$ By opening the ways in which subjects were entered into the pathway, the authors demonstrated improved adherence and expected outcomes. In particular, with regard to respiratory care in an in-patient setting, implementing management al- 


\section{EDITORIALS}

gorithms based on optimum care standards can be challenging. By instituting automatic triggers for implementation, care teams can better ensure that this occurs without subverting practitioners' autonomy to care for their patients based on their clinical judgment, improving outcomes and increasing the impact of practice improvement protocols. ${ }^{8}$

The outcomes of their efforts were highly convincing in support of these measures. The authors noted that admission to the ward from the emergency department was higher in the protocol phase and speculated that this may be due to improved awareness and comfort on behalf of physicians admitting these subjects to a non-ICU setting. Second, unplanned admissions to the ICU were down in the protocol phase, which is a strong testament to the success of the program. And last, the protocols in place resulted in a lower utilization of bronchodilator therapy in their institution, indicating that caregivers were either identifying subjects who did not require such therapy or were not using bronchodilator therapy as a surrogate for involvement of respiratory therapists in the continuing care of their patients. Together with fewer admissions to the ICU from the emergency department and a complete absence of returns to the ICU for respiratory complications during phase 2 of the study, these measures constituted a significant impact on respiratory care resource utilization.

The limitations of the study are not insignificant, however. Although the metrics studied are important and unquestionably had an impact on the subjects themselves, the authors were not able to demonstrate a significant difference in patient-centered outcomes, such as incidence of pneumonia, respiratory failure, atelectasis, or oxygen requirements. Ultimately, such measures should not only improve the care we deliver but directly impact the patients themselves in terms of ensuring their survival and their timely return to preinjury health status or their new optimal baseline, given their particular condition.

Patrick Greiffenstein MD

Department of Surgery/Critical Care

Louisiana State University Health Science Center

New Orleans, Louisiana

Terry L Forrette MHS RRT FAARC

Department of Cardiopulmonary Science

Louisiana State University Health Science Center

New Orleans, Louisiana

\section{REFERENCES}

1. Prin M, Li G. Complications and in-hospital mortality in trauma patients treated in intensive care units in the United States, 2013. Inj Epidemiol 2016;3:18.

2. Flagel BT, Luchette FA, Reed RL, Esposito TJ, Davis KA, Santaniello JM, Gamelli RL. Half-a-dozen ribs: the breakpoint for mortality. Surgery 2005;138(4):717-723; discussion 723-725.

3. Johnson JL, Haenel JB. Respiratory insufficiency. In: Mattox KL, Moore EE, Feliciano DV. Trauma, 7th edition. New York: McGrawHill; 2013:1055-1072.

4. Todd SR, McNally MM, Holcomb JB, Kozar RA, Kao LS, Gonzalez EA, et al. A multidisciplinary clinical pathway decreases rib fractureassociated infectious morbidity and mortality in high-risk trauma patients. Am J Surg 2006;192(6):806-811.

5. Ciesla DJ, Moore EE, Johnson JL, Burch JM, Cothren CC, Sauaia A. The role of the lung in postinjury multiple organ failure. Surgery 2005;138(4):749-757; discussion 757-758.

6. Hoyt DB, Simons RK, Winchell RJ, Cushman J, Hollingsworth-Fridlund P, Holbrook T, Fortlage D. A risk analysis of pulmonary complications following major trauma. J Trauma 1993;35(4):524-531.

7. Nyland BA, Spillman SK, Halub ME, Lamb KD, Jackson JA, Oetting TW, Sahr SM. A preventative respiratory protocol to identify trauma patients at risk for respiratory compromise on a general surgery inpatient ward. Respir Care 2016;61(12):••••.

8. Bagga S, Paluzzi DE, Chen CY, Riggio JM, Nagaraja M, Marik PE, Baram M. Better ventilator settings using a computerized clinical tool. Respir Care 2014;59(8):1172-1177. 